\title{
A PONDERAÇÃO JUDICIAL DE PRINCÍPIOS CONSTITUCIONAIS NO NEOCONSTITUCIONALISMO*
}

\author{
Bárbara Dayana Brasil ${ }^{* *}$
}

\section{RESUMO}

Diante da superação do Estado Legislativo e da emergência de um Estado Constitucional, pode-se claramente perceber que o constitucionalismo contemporâneo tem definido suas características principais notadamente a partir dos últimos cinqüenta anos, sobretudo, após a Segunda Guerra Mundial sofrendo transformações capazes de caracterizá-lo como um modelo dinâmico, em que por meio das modificações operadas pode-se falar na existência de um Estado neoconstitucional. Desta forma, necessário se faz analisar, ainda que de modo não exaustivo, as principais questões atinentes a forma em que a jurisdição constitucional opera com as idéias neoconstitucionalistas em matéria de princípios constitucionais. O presente estudo destina-se a observar a questão da colisão de princípios constitucionais, sob o paradigma do neoconstitucionalismo, a fim de demonstrar como a técnica da ponderação judicial pode auxiliar na solução de possíveis conflitos. Busca-se, assim, defender a garantia dos princípios constitucionais como direitos fundamentais, estruturantes da própria noção de Estado Democrático de Direito, a serem assegurados por meio do exercício da jurisdição constitucional.

Palavras-Chave: Neoconstitucionalismo. Princípios Constitucionais. Colisão de Princípios. Ponderação Judicial. Jurisdição Constitucional.

Sumário: INTRODUÇão. 1 A EMERGÊNCIA DO NeOconstitucionalismo. 2 A Colisão de PRINCíPIOS CONSTITUCIONAIS. 3. A PONDERAÇÃo JUdicial DE PRINCíPIOS

* Artigo produzido como requisito parcial para aprovação na disciplina Teoria dos Princípios Constitucionais, ministrada pelo Professor Doutor Paulo Cruz, da Linha de Pesquisa Hermenêutica e Principiologia Constitucional do Programa de Mestrado em Ciência Jurídica da Universidade do Vale do Itajaí.

** Mestranda do Programa de Mestrado em Ciência Jurídica da Universidade do Vale do Itajaí. Especialista em Direito Administrativo pelo Instituto de Direito Romeu Felipe Bacellar. Advogada. Professora de Direito Administrativo do Curso de Direito da Faculdade Mater Dei - Pato Branco (PR). Email: barbaradbrasil@yahoo.com.br 
CONSTITUCIONAIS. CONCLUSÃO. REFERÊNCIAS.

\section{INTRODUÇÃO}

O aumento significativo na demanda por justiça na sociedade brasileira decorrente da redescoberta da cidadania e da conscientização das pessoas acerca de seus próprios direitos, associado à circunstância da Constituição Federal de 1988 ter assegurado novos direitos, tem propiciado um momento próprio à discussão acerca do papel do Poder Judiciário, nesse ambiente de desenvolvimento político.

Trata-se de um momento novo na cultura jurídica, em que diante da velocidade da informação e dos acontecimentos verificados, espera-se do intérprete que esteja aberto a uma nova forma de olhar a ciência jurídica.

Pode-se afirmar, de acordo com as palavras de Luís Roberto BARROSO, que

talvez esta seja uma boa explicação para o recurso recorrente aos prefixos pós e neo: pósmodernidade, pós-positivismo, neoliberalismo, neoconstitucionalismo. Sabe-se que veio depois e que tem a pretensão de ser novo. Mas ainda não se sabe bem o que é. Tudo é ainda incerto. Poder ser avanço. Pode ser uma volta ao passado. Pode ser apenas um movimento circular, uma dessas guinadas de 360 graus. ${ }^{1}$

Especificamente sob as interpretações realizadas pelo Poder Judiciário é que recaem de modo mais contundente esperanças profundas de transformação, sobretudo, quanto aos direitos assegurados pela Constituição Federal, dos quais se espera uma visão construtiva.

Exatamente com base nesta perspectiva aberta e inovadora é que se pretende analisar o papel exercido pelo Poder Judiciário, notadamente quando diante da

1 BARROSO, Luís Roberto. Neoconstitucionalismo e constitucionalização do direito. Disponível em: http://jus2.uol.com.br/doutrina/texto.asp?id=7547 Acesso em: 16 jul. 2007. 
necessária interpretação de princípios constitucionais, que por sua abrangência e amplitude, acabam freqüentemente entrando em rota de colisão, exigindo que o intérprete proceda a sua adequada ponderação.

Vislumbra-se, com isso, a necessidade de analisar, de que forma se dará a atuação jurisdicional quando diante de uma situação de conflito entre princípios constitucionais, contextualizando-se com esta nova perspectiva da ciência jurídica denominada por muitos como neoconstitucionalismo(s). ${ }^{2}$

Através do presente estudo, busca-se reunir elementos capazes de conduzir e instigar a uma reflexão crítica acerca do tema. Para tanto, parte-se de uma análise que pretende contextualizar a emergência do neoconstitucionalismo com uma hermenêutica constitucional pautada em princípios constitucionais.

Na sequiência, busca-se verificar a atuação do Poder Judiciário quando diante da situação de colisão de tais princípios para, ao final, demonstrar a necessidade de se conceder liberdade ao julgador, para no caso concreto, realizar a harmonização entre eles por meio da chamada ponderação judicial.

Justifica-se, portanto, a opção pelo assunto, na medida em que a tendência é que na prática, efetivamente, se verifiquem situações em que o Poder Judiciário será provocado a manifestar-se acerca de choques entre bens jurídicos que se contrapõem, caracterizando um momento em que a atuação do intérprete criará o Direito aplicável ao caso concreto.

Busca-se, por fim, investigar, desta forma, as causas e efeitos que desencadearam este novo modo de pensar a ciência jurídica e que autoriza o Poder Judiciário a atuar ativamente na construção e no desenvolvimento do Estado Democrático de Direito. 


\section{A EMERGÊNCIA DO NEOCONSTITUCIONALISMO}

As bases históricas sobre as quais se funda o Estado Constitucional de Direito, remontam inicialmente a um Estado baseado no absolutismo monárquico que imperou durante os séculos XVII e XVIII, em que a regulamentação da vida em sociedade estava exclusivamente nas mãos do Soberano.

Daí porque, pode-se afirmar, segundo Thomas HOBBES, que ao soberano "competia, portanto, ser Juiz, e prescrever as Regras para distinguir entre o Bem e o Mal, regras estas que são leis; em conseqüência, nele que reside o Poder Legislativo." ${ }^{3}$ Cabia, portanto, ao Soberano o exercício dos poderes do Estado, entre os quais, o de executar, legislar e julgar os conflitos possivelmente existentes.

Com o desenvolvimento da noção de Estado, este modelo deu lugar a um sistema de poder, no século seguinte, em que a supremacia política e jurídica concentrou-se nas mãos do Legislativo, que passou a ser o soberano representante da nação.

De acordo com Luiz Henrique CADEMARTORI,

nesse novo modelo sob o império da lei, que passou a ser considerada a instancia máxima de representação contra o arbítrio dos governantes, abriram-se novas oportunidades de ampliar a discricionariedade do poder estatal. Isto porque a lei, como instância soberana, não obedecia ela própria, a nenhuma limitação de conteúdo quanto ao que pudesse ser legislado. ${ }^{4}$

Diante deste cenário, denominado Estado Liberal, era a lei que regulamentava os aspectos mais relevantes da vida em sociedade, buscando compatibilizar o interesse privado de cada um com o interesse de todos, por meio de direitos convencionados perante o Estado.

${ }^{2}$ Vide obra de CARBONNEL, Miguel. Neoconstitucionalismo (s). Madrid: Trotta, 2003.

${ }^{3}$ HOBBES, Thomas. Leviatã ou matéria, forma e poder de um Estado eclesiástico e civil. Trad. Rosina D’Angina. São Paulo: Ícone, 2000, p. 151.

${ }^{4}$ CADEMARTORI, Luiz Henrique Urquhart. Discricionariedade administrativa no Estado 
Cumpre destacar, que sob este paradigma de Estado, a Constituição é compreendida como um instrumento de governo, organização e limitação do poder político, em que se juridifica o Estado, que legitimado pelo Direito e pelo regime representativo, passa a ser concebido como Estado de Direito, como Estado Constitucional. ${ }^{5}$

Na seqüência, com a crise deste paradigma de Estado tem início uma fase da história que se convencionou chamar de Constitucionalismo Social decorrente do Estado Social, que surge após a primeira guerra e se firma após a segunda, intervindo na economia, compensando desigualdades sociais por meio da prestação estatal de serviços e da concessão de direitos sociais.

Segundo este paradigma, o Direito, nas palavras de Marcelo Cattoni de Andrade,

passa a ser interpretado como sistema de regras e de princípios otimizáveis, consubstanciadores de valores fundamentais, bem como de programas de fins, realizáveis no limite do possível. A Constituição é o estatuto jurídico-político fundamental do Estado e da sociedade (...). ${ }^{6}$

Desta forma, com a crescente crise do Estado Social aliado ao surgimento de movimentos sociais que passam a denunciar as limitações das políticas públicas, bem como, as contradições entre capitalismo e socialismo, começa-se a falar em Estado Democrático de Direito, Estado Constitucional de Direito, Estado Constitucional Democrático.

Em verdade, trata-se, de um novo momento, em que o Direito, justificado nos princípios democráticos assume, então, o lugar deixado pela eticidade, pois, ao direito também cumpre satisfazer as precárias condições de uma integração social.

Constitucional de Direito. Curitiba: Juruá, 2006, p. 61

5 OLIVEIRA, Marcelo Andrade Cattoni de. Direito constitucional. Belo Horizonte: Mandamentos, 2002, p. 56.

${ }^{6}$ Ibidem, loc. cit. 
Tem-se, a partir desta perspectiva, um novo momento para o direito constitucional que se destaca, em nível mundial, especialmente após a Segunda Grande Guerra, e no Brasil, com a Constituição de 1988.

A influência operada no Direito fora de tal ordem que, fez com que se redefinisse o lugar da Constituição permitindo uma interpretação diferenciada das instituições contemporâneas, aproximando-se as idéias de constitucionalismo e de democracia, produzindo verdadeiramente uma nova forma de organização política.

Isto pode ser facilmente verificado, no caso brasileiro, pois, segundo Barroso,

sob a Constituição de 1988, o direito constitucional no Brasil passou da desimportância ao apogeu em menos de uma geração. Uma Constituição não é só técnica. Tem de haver, por trás dela, a capacidade de simbolizar conquistas e mobilizar o imaginário das pessoas para novos avanços. O surgimento de um sentimento constitucional no País é algo que merece ser celebrado. ${ }^{7}$

Verifica-se assim, que a perspectiva teórico-filosófica também passa a assumir uma nova postura na medida em que se caracteriza pela superação de modelos puros por um conjunto abrangente de idéias que podem ser enquadradas sob a definição de pós-positivismo e que representam o sentimento constitucional ora mencionado.

As consequiências desta mudança, ocasionadas pela superação do jusnaturalismo e pelo fracasso político do positivismo abriram as portas para uma série de reflexões sobre o Direito, que desencadearam na emergência do chamado neoconstitucionalismo, cujo significado representa uma nova cultura jurídica que pode incorporar a um só tempo, um modelo de Estado de Direito, uma teoria do Direito e uma ideologia. ${ }^{8}$

O conhecimento convencional sobre o direito constitucional passa, com a emergência do neconstitucionalismo, a ir além da legalidade estrita, sem desprezar o direito posto, procurando empreender uma leitura moral do Direito, sem, contudo,

\footnotetext{
${ }^{7}$ BARROSO. Neoconstitucionalismo ..., p. 3.

${ }^{8}$ SACHÍS, Luis Prieto. Neoconstitucionalismo y ponderación judicial. In: CARBONELL, Miguel. Neoconstitucionalismo(s). Madrid: Trotta, 2003. p. 123.
} 
recorrer a categorias metafísicas.

A interpretação e aplicação do ordenamento jurídico passam a ser inspiradas por uma teoria de justiça, que, de acordo com Barroso abriga, neste paradigma em construção, a atribuição de normatividade aos princípios e a definição de suas relações com valores e regras, a reabilitação da razão prática e da argumentação jurídica, a formação de uma nova hermenêutica constitucional, e o desenvolvimento de uma teoria de direitos fundamentais edificada sobre o fundamento da dignidade humana. ${ }^{9}$

Nesse ambiente, pode-se afirmar que ocorre a emergência do neoconstitucionalismo como uma nova forma de interpretar o próprio constitucionalismo, só que agora, reunindo elementos que com freqüência caminharam separados, ${ }^{10}$ quais sejam, o forte conteúdo normativo e a garantia jurisdicional dos direitos consagrados.

\section{A COLISÃO DE PRINCÍPIOS CONSTITUCIONAIS}

Diante das idéias trazidas com o neoconstitucionalismo verifica-se que grandes transformações foram operadas no conhecimento convencional do direito constitucional, entre as quais, inserem-se o reconhecimento da força normativa da Constituição, a expansão da jurisdição constitucional e o desenvolvimento de uma nova interpretação constitucional.

Essas transformações permitiram, no plano prático, que o Direito passasse a enfrentar novas questões entre as quais, a colisão de princípios constitucionais.

Isto porque, os princípios constitucionais, segundo Celso Ribeiro Bastos, são aqueles valores albergados pelo Texto Maior a fim de dar sistematização ao documento constitucional, de servir como critério de interpretação e finalmente, o que

\footnotetext{
${ }^{9}$ BARROSO. Neoconstitucionalismo ..., p. 5.

${ }^{10}$ SACHÍS, op. cit., p. 124.
} 
é mais importante, espraiar os seus valores, pulverizá-los sobre todo o mundo jurídico $^{11}$.

Diante disso, vislumbra-se que na medida em que o Constituinte inseriu no Texto Maior alguns princípios constitucionais pretendeu conferir aos mesmos a força normativa característica dos direitos fundamentais ao dispô-los com os demais direitos e garantias individuais, a fim de assegurar sua observância como valores fundamentais da ordem jurídica.

De acordo com Barroso, o reconhecimento da normatividade dos princípios e sua distinção qualitativa em relação às regras é um dos símbolos do pós positivismo. Princípios não são, como as regras, comandos imediatamente descritivos de condutas específicas, mas sim normas que consagram determinados valores ou indicam fins públicos a serem realizados por diferentes meios. ${ }^{12}$

Nesta perspectiva, considerando-se os princípios constitucionais como Direitos Fundamentais, porque representativos dos bens jurídicos mais caros da sociedade, entende-se que todo o ordenamento jurídico deve ser compreendido e aplicado a partir deles, a fim de que efetivamente se realize a chamada filtragem constitucional que, nas palavras de Paulo Ricardo Schier, significa

a normatividade Constitucional impõe-se de maneira positiva, exigindo que se faça uma leitura (ou releitura) da ordem infraconstitucional através daquela. Em outras palavras, os valores constitucionais primeiramente devem buscar realização, impondo-se mediante a ordem infraconstitucional. ${ }^{13}$

Assim sendo, os princípios constitucionais impõem sua observância não apenas sobre a aplicação da legislação infraconstitucional como também sobre a criação de normas processuais infraconstitucionais, sob pena de se verificar uma

${ }^{11}$ BASTOS, Celso Ribeiro. Curso de direito constitucional. 21. ed. São Paulo: Saraiva, 2000, p. 154.

${ }^{12}$ BARROSO. Neoconstitucionalismo ..., p. 3.

${ }^{13}$ SCHIER, Paulo Ricardo. Filtragem constitucional. Porto Alegre: Fabris, 1999, p. 103. 
flagrante inconstitucionalidade por violação a Direitos Fundamentais, os quais, de acordo com Luigi Ferrajoli,

equivalem a vínculos de sustancia y no de forma, que condicionan la validez sustancial de las normas producidas y expresan, al mismo tiempo, los fines a que está orientado ese moderno artificio que es el Estado constitucional de derecho. ${ }^{14}$

Daí exatamente por que foram erigidos à categoria de Direitos Fundamentais, alguns princípios constitucionais, cuja menor densidade jurídica impede que se extraia de suas normas, abstratamente, a solução completa das questões sobre as quais incidem, impondo-se a atuação do intérprete na definição concreta de seu sentido e alcance.

Isto se dá na medida em que a amplitude e abrangência de seu conteúdo permitem, em sua abertura, que exista a colisão de normas constitucionais. Tal ocorre justamente porque, segundo Schier,

os princípios encerram grau de abstração maior que os demais elementos do sistema, possuindo características específicas que vão, desde a abstratalidade, indeterminação, vaguidade e baixa densidade normativa, até funcionalidade diversa (mormente otimização do sistema e funções hermenêuticas. ${ }^{15}$

Tais características demonstram a abertura do sistema jurídico, que permite verificar o direito como um sistema dinâmico, em constante evolução e construção, e que estabelece um diálogo permanente entre seus princípios, que muitas vezes conduzirá a um choque entre eles.

Sobre isso, Barroso acentua que,

${ }^{14}$ FERRAJOLI, Luigi. Derechos y garantías: la ley del más débil. Trad. Perfecto Andres Ibanez. Madrid: Trotta, 1999, p. 22.

${ }^{15}$ SCHIER, op. cit., p. 89. 
As Constituições modernas são documentos dialéticos, que consagram bens jurídicos que se contrapõem. Há choques potenciais entre a promoção do desenvolvimento e a proteção ambiental, entre a livre iniciativa e a proteção do consumidor. No plano dos direitos fundamentais, a liberdade religiosa de um indivíduo pode conflitar-se com a de outro, o direito de privacidade e a liberdade de expressão vivem em tensão contínua, a liberdade de reunião de alguns pode interferir com o direito de ir e vir dos demais. ${ }^{16}$

Com base no panorama exposto, pode-se pensar, segundo Sachís, que as “Constituições do neoconstitucionalismo são um despropósito, um monumento à antinomia: um conjunto de normas contraditórias entre si que se sobrepõem de modo permanente dando lugar a soluções díspares."

$\mathrm{Na}$ verdade, verifica-se ser impossível falar em normas constitucionais, e em especial em princípios constitucionais, com sentido unívoco, com soluções prontas aos possíveis conflitos existentes ${ }^{18}$. Na medida em que o neoconstitucionalismo trouxe à tona uma nova hermenêutica constitucional, caracterizada por uma perspectiva principiológica do Direito a abertura e o diálogo torna-se constantes na sua interpretação.

Isto porque, no que concerne às regras, que são mais objetivas e específicas, a solução para a hipótese de colisão encontra-se, segundo Ronald Dworkin, a maneira do tudo ou nada. Dados os fatos que uma regra estipula, então ou a regra é válida, e neste caso a resposta que ela fornece deve ser aceita, ou não é válida e neste caso em nada contribui para a decisão. ${ }^{19}$

Já quanto aos princípios, entende-se, em conformidade com Paulo Márcio Cruz e Rogério Zuel Gomes, quando afirmam que por seu "caráter eminentemente axiológico, afastam-se muito da regra jurídica, servindo como parâmetro para a sua

${ }^{16}$ BARROSO. Neoconstitucionalismo ..., p. 6.

${ }^{17}$ SACHIS, op. cit., p. 134.

18 Em que pese, de acordo com Lenio Luiz STRECK, "expressivos setores da doutrina brasileira trabalham (ainda) na perspectiva de que o processo interpretativo possibilita que se alcance a 'interpretação correta', “o sentido exato da norma', 'o exclusivo conteúdo/sentido da lei', 'o verdadeiro significado do vocábulo', 'o real sentido da regra jurídica', etc." (STRECK, Lenio Luiz. Hermenêutica jurídica e $(\mathrm{m})$ crise: uma exploração hermenêutica da construção do Direito. 3. ed. Porto Alegre: Livraria do Advogado, 2001, p. 104).

${ }^{19}$ DWORKIN, Ronald. Levando os direitos a sério. São Paulo: Martins Fontes, 2002, p. 39. 
construção, porém sem compartilhar de praticamente nenhuma de suas características.",20

Desta forma, percebe-se que os princípios coadunam-se com uma textura aberta do direito, voltada aos valores, de modo que, em conformidade com Herbert Hart, tem-se que,

a textura aberta do direito significa que há, na verdade, áreas de conduta em que muitas coisas devem ser deixadas para serem desenvolvidas pelos tribunais ou pelos funcionários, os quais determinam o equilíbrio, à luz das circunstâncias, entre interesses conflitantes que variam em peso, de caso para caso. ${ }^{21}$

Essa textura aberta é exatamente o que permite a ocorrência de colisão de princípios constitucionais, que decorrem em certa medida da impossibilidade humana de prever todas as situações e antecipar todos os conflitos possíveis, razão pela qual, entende-se que, nestas hipóteses, deve ser atribuído ao julgador um poder discricionário para solucionar a lide, o que deverá ser feito em função do critério da ponderação.

\section{A PONDERAÇÃO JUDICIAL DE PRINCÍPIOS CONSTITUCIONAIS}

Diante do que se expôs anteriormente, verifica-se que, no que concerne às regras, não há maiores controvérsias quanto à solução para possíveis conflitos existentes, resolvendo-se por meio dos critérios tradicionais de solução de conflitos normativos, quais sejam, hierárquico, cronológico e da especialização.

Ocorre que, o objeto do presente estudo concentra-se na existência de conflitos entre princípios constitucionais em que a proposta de solução reside na ponderação

${ }^{20}$ CRUZ, Paulo Márcio; GOMES, Rogério Zuel. Princípios constitucionais e direitos fundamentais. Curitiba: Juruá, 2007, p. 29-30. 
judicial que, segundo Barroso e Ana Paula de Barcellos, consiste, "em uma técnica de decisão jurídica aplicável a casos difíceis, em relação aos quais a subsunção se mostrou insuficiente, especialmente quando uma situação concreta dá ensejo à aplicação de normas de mesma hierarquia que indicam soluções diferenciadas". ${ }^{22}$

Trata-se, segundo Sachís, da "ação de considerar imparcialmente os aspectos contrapostos de uma questão ou o equilíbrio entre o peso de duas coisas". ${ }^{23}$

O processo de ponderação de normas, bens ou valores, pelo intérprete envolve duas etapas, a) concessões recíprocas, procurando preservar o máximo possível de cada um dos interesses em disputa ou, no limite, b) procederá a escolha do direito que irá prevalecer, em concreto, por realizar mais adequadamente a vontade constitucional. O conceito chave na matéria é o princípio instrumental da proporcionalidade ou razoabilidade. ${ }^{24}$

Até porque, destaca Sachís, que, "certamente no mundo do direito o resultado da ponderação não será necessariamente o equilíbrio entre tais interesses, razões ou normas; ao contrário, o habitual é que a poderação desemboque no triunfo de algum deles no caso concreto". 25

Desta forma, entende-se que, em abstrato, o intérprete estará operando com princípios jurídicos de mesmo valor, de modo que se torna possível conviver em um sistema normativo com todos estes valores. Entretanto, em concreto, quando houver a colisão dos mesmos será necessário realizar a ponderação, cuja solução poderá consistir no triunfo de um sobre o outro.

Barroso exemplifica mencionando que são exemplos da ponderação de

${ }^{21}$ HART, Hebert. O conceito de direito. 3. ed. Lisboa: Calouste Gulbenkian, 2001, p. 148.

${ }^{22}$ BARROSO, Luís Roberto; BARCELLOS, Ana Paula de. O começo da história. A nova interpretação constitucional e o papel dos princípios no direito brasileiro. In: BARROSO, Luís Roberto (org). A nova interpretação constitucional: ponderação, direitos fundamentais e relações privadas. Rio de Janeiro: Renovar, 2003. p. 345-346.

${ }^{23}$ SACHÍS, op. cit., p. 137.

${ }^{24}$ BARROSO. Neoconstitucionalismo ..., p. 6.

${ }^{25}$ SACHIS, op. cit., p. 137. 
valores:

a) a relativização da coisa julgada (colisão entre o princípio da segurança jurídica e valores tais como justiça); b) eficácia horizontal dos direitos fundamentais (aplicação das normas constitucionais às relações privadas); c) contraste entre a liberdade de expressão e o direito à informação com o direito à honra, à imagem e à privacidade. ${ }^{26}$

Tais são, portanto, algumas demonstrações de que a nova cultura jurídica impõe ao direito a necessidade de flexibilizar-se, de dialogar e de retirar-se da estabilidade que pairou sob as técnicas de interpretação durante um longo tempo.

Veja-se que com o conteúdo princípiológico por meio do qual se funda a ordem neoconstitucional tem-se, segundo Schier, que a própria idéia de justiça "fica sujeita a relações de ponderação diante de cada caso concreto. Ou seja, o conceito de justiça é relido e atualizado à luz de cada caso concreto posto diante do juiz." ${ }^{27}$

Rompe-se com a interpretação e aplicação formalista e positivista do direito, permitindo-se ao julgador que avalie a justiça ou injustiça de sua decisão no caso concreto, tratando-se, pois, de tarefa a ser desenvolvida propriamente pelo juiz, o que não significa que o direito será aberto a volutarismos.

Note-se, de acordo com Barroso e Barcellos que,

a existência de ponderação não é um convite para o exercício indiscriminado de ativismo judicial. O controle de legitimidade das decisões obtidas mediante ponderação tem sido feito através do exame da argumentação desenvolvida. Seu objetivo, de forma bastante simples, é verificar a correção dos argumentos apresentados em suporte de uma determinada conclusão ou ao menos a racionalidade do raciocínio desenvolvido em cada caso, especialmente quando se trate do emprego da ponderação. ${ }^{28}$

Portanto, resta claro que, se por um lado o juiz terá que realizar a ponderação de bens constitucionalmente tutelados, no caso concreto, por outro lado, não se trata de

\footnotetext{
${ }^{26}$ BARROSO; BARCELLOS, op. cit, p. 349.

${ }^{27}$ SCHIER, op. cit., p. 131.
} 
permitir a ele voluntarismos e subjetivismos, uma vez que a sua decisão estará sujeita ao controle de racionalidade por meio da teoria da argumentação.

Note-se que, neste sentido Sachís, afirma que

isto não significa que a ponderação estimule um subjetivismo desembocado, nem que seja método vazio ou que conduza a qualquer conseqüência, pois se não dá garantia a uma resposta para todo caso prático, nos indica que há de fundamentar para resolver um conflito constitucional. ${ }^{29}$

Da mesma forma, Cruz e Zuel afirmam que,

O Estado Democrático de Direito exige a controlabilidade das decisões, e tanto quanto possível a minimização das paixões e racionalidade do julgador. É por isso que se diz póspositivista a metódica por nós adotada. Não se ignora o texto, mas ele deve ser transcendido pela práxis do operador do direito. ${ }^{30}$

Tem-se que, diante do pós-positivismo, em última análise decorrente da emergência do neoconstitucionalismo, em que a interpretação do direito constitucional encontra-se intimamente ligada a valores e princípios e conseqüentemente à possibilidade de colisões, a ponderação judicial resulta num processo hermenêutico necessário e condizente com a textura aberta do direito.

Não se trata, como já afirmado, de ativismo judicial indiscriminado, até porque a sua aplicação reclama uma teoria da argumentação capaz de garantir a racionalidade das decisões emanadas, mas trata-se sem dúvida, de desgarrar o direito do formalismo e de permitir a ele o efetivo ingresso na fase pós-positivista, neoconstitucional, na qual tudo o que se sabe sobre seus efeitos é que, "poder ser avanço. Pode ser uma volta ao passado. Pode ser apenas um movimento circular, uma

\footnotetext{
${ }^{28}$ BARROSO; BARCELLOS, op. cit., p. 350.

${ }^{29}$ SACHIS, op. cit., p. 151.

${ }^{30}$ CRUZ; GOMES, op. cit., p. 23.
} 
dessas guinadas de 360 graus". 31

\section{CONCLUSÃO}

- Com base no que fora verificado, pode-se afirmar que a emergência do neoconstitucionalismo acarretou uma influência importante na nova interpretação do direito constitucional, redefinindo o lugar da Constituição e permitindo uma interpretação diferenciada das instituições contemporâneas, aproximando-se as idéias de constitucionalismo e de democracia, produzindo verdadeiramente uma nova forma de organização política;

- Entre as grandes transformações que foram operadas no conhecimento convencional do direito constitucional, insere-se o reconhecimento da força normativa da Constituição, a expansão da jurisdição constitucional e o desenvolvimento de uma nova interpretação constitucional;

- No plano prático, isto significou que o Direito passasse a enfrentar novas questões entre as quais, a colisão de princípios constitucionais que dada a sua abrangência e amplitude permitem que os bens jurídicos por eles tutelados se confrontem;

- Tais características demonstram a abertura do sistema jurídico, que permite verificar o direito como um sistema dinâmico, em constante evolução e construção, e que estabelece um diálogo permanente entre seus princípios, que muitas vezes conduzirá a um choque entre eles;

- A maneira para solucionar os conflitos entre princípios é diferente do que concerne às regras, que são mais objetivas e específicas, a solução para a hipótese de conflito encontra-se, a maneira do tudo ou nada;

\footnotetext{
${ }^{31}$ BARROSO. Neoconstitucionalismo ..., op. cit.
} 
- No caso dos princípios, a forma adequada para a solução na hipótese de colisão diz respeito ponderação judicial que se dá em duas etapas, através de: a) concessões recíprocas, procurando preservar o máximo possível de cada um dos interesses em disputa ou, no limite, b) procederá a escolha do direito que irá prevalecer, em concreto, por realizar mais adequadamente a vontade constitucional;

- A ponderação rompe com a interpretação e aplicação formalista e positivista do direito, permitindo ao julgador que avalie a justiça ou injustiça de sua decisão no caso concreto;

- Por meio da ponderação, deve-se destacar, não se está abrindo a interpretação de normas constitucionais à possíveis voluntarismos e subjetivismos do intérprete, até porque, a sua decisão estará sujeita ao controle de racionalidade em função da teoria da argumentação;

- Assim, se a solução para a questão não parece, e efetivamente não é, simples, entende-se que o propósito do presente estudo se cumprirá na medida em que, não pretendendo resolver o problema, tenha alertado e suscitado a questão de modo a instigar uma reflexão sobre as possíveis influências do neoconstitucionalismo sobre ponderação judicial de princípios constitucionais.

\section{REFERÊNCIAS}

BARROSO, Luís Roberto. Neoconstitucionalismo e constitucionalização do direito. Disponível em: http://jus2.uol.com.br/doutrina/texto.asp?id=7547 Acesso em: 16 jul. 2007.

; BARCELLOS, Ana Paula de. O começo da história. A nova interpretação constitucional e o papel dos princípios no direito brasileiro. In: BARROSO, Luís Roberto (org). A nova interpretação constitucional: ponderação, direitos fundamentais e relações privadas. Rio de Janeiro: Renovar, 2003.

BASTOS, Celso Ribeiro. Curso de direito constitucional. 21. ed. São Paulo: Saraiva, 2000 . 
CADEMARTORI, Luiz Henrique Urquhart. Discricionariedade administrativa no Estado Constitucional de Direito. Curitiba: Juruá, 2006.

CARBONNEL, Miguel. Neoconstitucionalismo (s). Madrid: Trotta, 2003.

CRUZ, Paulo Márcio; GOMES, Rogério Zuel. Princípios constitucionais e direitos fundamentais. Curitiba: Juruá, 2007.

DWORKIN, Ronald. Levando os direitos a sério. São Paulo: Martins Fontes, 2002.

FERRAJOLI, Luigi. Derechos y garantías: la ley del más débil. Trad. Perfecto Andres Ibanez. Madrid: Trotta, 1999.

HART, Hebert. O conceito de direito. 3. ed. Lisboa: Calouste Gulbenkian, 2001.

HOBBES, Thomas. Leviatã ou matéria, forma e poder de um Estado eclesiástico e civil. Trad. Rosina D’Angina. São Paulo: Ícone, 2000.

OLIVEIRA, Marcelo Andrade Cattoni de. Direito constitucional. Belo Horizonte: Mandamentos, 2002.

SACHÍS, Luis Prieto. Neoconstitucionalismo y ponderación judicial. In: CARBONELL, Miguel. Neoconstitucionalismo(s). Madrid: Trotta, 2003.

SCHIER, Paulo Ricardo. Filtragem constitucional. Porto Alegre: Fabris, 1999.

STRECK, Lenio Luiz. Hermenêutica jurídica e $(m)$ crise: uma exploração hermenêutica da construção do Direito. 3. ed. Porto Alegre: Livraria do Advogado, 2001 . 